\section{Genetic determination of characteristics related to semi-mechanized coffee harvests}

\author{
Rodrigo Elias Batista Almeida Dias ${ }^{1}$, Rafael Antônio Almeida \\ Dias $^{1}$, César Elias Botelho ${ }^{2}$, Juliana Costa de Rezende \\ Abrahão ${ }^{2^{*}}$, Tiago Teruel Rezende ${ }^{3}$ and Gladyston Rodrigues \\ Carvalho $^{3}$
}

\begin{abstract}
Brazilian coffee cultivation was boosted over the last few decades by the mechanization of various field operations. Considering the influence of genetic factors on coffee harvesting efficiency, we aimed to evaluate the use of mechanized harvesting characteristics as a criterion to select progenies derived from 'catu' germplasm, previously evaluated for agronomic characteristics, resistance to rust and cercosporiosis. We also investigated genotypic and phenotypic correlations between semi-mechanized harvesting characteristics. Ten progenies of Coffea arabica L. were analyzed in two experimental farms during two consecutive harvests. Genetic parameters were evaluated to trace selection strategies. Four progenies that were suitable for mechanization were selected, supporting our hypothesis of the use of harvest characteristics as selection criteria.
\end{abstract}

Keywords: Coffea arabica, genetic improvement, BLUP, correlations.

\section{INTRODUCTION}

The broad scientific and technological development of Brazilian coffee cultivation over the last few decades was boosted by the use of mechanization in various field operations. This mechanization process eases and reduces the labor involved in farming, improves timeliness of agricultural operations, ensures the efficient use of resources, and relieves labor shortages (Ferreira Junior et al. 2016). Mechanization also enables the cultivation in mountainous lands. These facts have generated a demand for coffee cultivars to meet the requirements of handling by technologically advanced systems.

In this sense, the intrinsic characteristics of the Coffea arabica ideotypes that allow the mechanized or semi-mechanized harvesting must be incorporated into the plant in order to obtain genotypes with an aptitude for mechanization: adequate structure, size, and form (Huang and Zou 2018). Besides the yield, genetic adaptation involves detachment strength, defoliation, vegetative vigor after harvesting, and efficiency of fruit harvest. Despite the importance of this process for coffee production, genetic studies regarding breeding for mechanized harvesting have not yet been performed. The understanding of these characteristics could be the first step.
Crop Breeding and Applied Biotechnology 20(1): e218820116, 2020 Brazilian Society of Plant Breeding. Printed in Brazil http://dx.doi.org/10.1590/198470332020v20n1n16

\footnotetext{
*Corresponding author: E-mail: julianacosta@epamig.br (iD) ORCID: 0000-0002-6026-7634
}

Received: 10 April 2018 Accepted: 18 November 2019 Published: 28 February 2020

${ }^{1}$ Universidade Federal de Lavras, Departamento de Fitotecnia, 37.200-000, Lavras, MG, Brazil

${ }^{2}$ Empresa de Pesquisa Agropecuária de Minas Gerais, Unidade Sul, Campus Universidade Federal de Lavras, 37.200-000, Lavras, MG, Brazil

${ }^{3}$ Universidade José do Rosário Vellano, Campus Universitario, 37.130-000, Alfenas, MG, Brazil 
Given the recent growth in mechanized harvesting of coffee in Brazil, the relevance of this crop to the country, and finally, the lack of extant cultivars with this aptitude, this work aimed to evaluate the use of semi-mechanized harvesting characteristics as criteria for the selection of progenies derived from 'Icatu' germplasm, that was previously evaluated for agronomic characteristics and resistance to rust and cercosporiosis (Pereira et al. 2013). Additionally, we estimated genetic parameters for these characteristics, once they provided information on the possibility of genetic gain and helped to inform decisions on breeding practices. We also investigated genotypic and phenotypic correlations between the characteristics, because knowledge of these correlations may help in planning efficient breeding programs.

\section{MATERIAL AND METHODS}

Thirty-three $F_{3: 4}$ progenies derived from 'Icatu' germplasm, obtained from the genetic breeding program of the Empresa de Pesquisa Agropecuária de Minas Gerais (EPAMIG), were evaluated in the Machado and São Sebastião do Paraíso municipalities, Brazil. Based on multiple agronomic characteristics and resistance to rust and cercosporiosis, Pereira et al. (2013) selected 10 of these progenies (A to J). In the current study, these assessments were continued for two consecutive years at the same sites. The experiments were installed in January 2007 in a randomized complete block design (RCBD) with four replications, spacing of $3.0 \mathrm{~m}$ between rows and $0.8 \mathrm{~m}$ between plants, using 10 plants per plot. We evaluated the harvests in 2014 and 2015.

Coffea arabica progenies A, B, C, D, I, and J were obtained from the cross between 'Icatu Amarelo IAC 2944' × 'Catuai Amarelo IAC 62'. Progeny E was derived from the cross between 'Icatu Vermelho IAC 4042' × 'IAC 5002', while progenies $F$ and $G$ were derived from the cross between 'Icatu Vermelho IAC 2944' $\times$ 'IAC 5002', and progeny H resulted from the cross between 'Icatu IAC 4040' × 'IAC 5002'. These progenies were evaluated based on the natural fruit drop (NFD), green and ripe fruit detachment strength (DFG, DFR), yield (YIE), defoliation in harvest (DF), vegetative vigor after harvesting $(\mathrm{VV})$, and harvest fruit efficiency (EH).

We quantified the natural coffee fall in sacks per hectare, collecting ground coffee in each plot, shaking in order to separate impurities, and the volume in liters of ground coffee per plant was measured. We evaluated the fruit detachment force using a portable digital dynamometer model DD-500. Harvesting was mechanically performed by two portable FS 85 STIHL $26 c c$ brush cutters operated by trained technicians, one on each side of the plant. The yield was evaluated by determining the number of $60-\mathrm{kg}$ bags of hulled coffee produced per hectare (bags ha-1). For the evaluation of vegetative vigor, we used grades from 1 to 10 according to the arbitrary scale proposed by Carvalho et al. (1979). During the evaluation of the defoliation, we separated and weighed fallen leaves on the cloths (defoliation) and registered the values in kilograms per plant.

The harvesting efficiency was determined by measuring the volume actually harvested in each plot, and was calculated according to the method proposed by Silva et al. (2015), given by the total volume collected divided by the outstanding load of the plot (total volume collected plus manual transfer in remaining fruits) and multiplied by 100 , as per the following equation: $E H(\%)=V T / P L^{*} 100$ where $E H$ is harvest efficiency (\%); VT is the total volume collected in each plot, $\mathrm{L} \mathrm{plant}^{-1}$; and $\mathrm{PL}$ is the pending load in $\mathrm{L} \mathrm{plant}^{-1}$. For a selective mechanical harvest, it was necessary to use the brush cutters once in the field, and the remaining fruits were collected by manual transfer. To record the load in bags per hectare, after semi-mechanized harvest, the fruits collected by manual transfer was added and the volume was recorded in liters of coffee per plot.

We estimated the variances and the prediction of random effects using the Restricted Maximum Likelihood/Best Linear Unbiased Prediction (REML/BLUP) procedure with the aid of the computational application, SELEGEN-REML/BLUP (Resende 2016). For this, we used the following equation: $y=X m+Z g+T p+W i+e$, where $y$ is the data vector, $m$ is the vector of the effects of evaluation-replicate-environmental combinations (assumed to be fixed) added to the general mean, $g$ is the vector of the genotypic effects (assumed to be random), $p$ is the vector of the plot effects (random), $i$ is the vector of the effects of the genotype $x$ environment interaction, and e is the error or residual vector (random). The uppercase letters represent the incident matrixes for the referenced effects.

Based on estimates of the components of variance, the genotypic variance, coefficient of determination associated with the random effects of the permanent environmental, as well as the effects of the genotype x environment interaction, the heritability of genotype mean, as well as the genotype correlation between performance in the environments, 
were estimated as described in Resende (2016). The variance tests associated with the random effects were made via a likelihood ratio test with significance set to $5 \%$. Due to the objective of this work, EH was chosen as the main criterion for selection. We additionally estimated the selection gain of NDF, VV, DFR, and DFG, based on the analysis of genetic parameters of these characteristics. Genetic correlations between the evaluated characteristics were estimated using the Genes program (Cruz 2013).

The mean values of the studied variables were standardized (zero mean and unit variance) and used for principal component analysis to identify variability between progenies and also the phenotypic correlations. The sites and harvest were used in principal component analysis as complementary qualitative variables to group the progenies in relation to location and season. The analysis was performed using R software (R Core Team 2019).

\section{RESULTS AND DISCUSSION}

The principal component analysis indicated contrasting behavior of the progenies in the two evaluation sites and also in the two harvests. The progenies from Machado presented higher values of DFG, DFR and DF and lower values for EH than the similar progenies from São Sebastião do Paraiso in the first harvest (Figure 1). Even in the second harvest, the progenies showed different behavior at both locations: those grown in Machado had higher values of DF, NFD, and YIE than those in São Sebastião do Paraiso, which showed higher values for VV. In São Sebastião do Paraíso, progenies that presented higher VV had lower YIE, NFD, and DF in the second harvest and had higher EH and lower the DFG and DFR in the first harvest. In general, the progenies from Machado had greater genetic variability than those from São Sebastião do Paraíso, indicating the influence of environment. The progeny F had similar scores for YIE and NFD regardless of site and harvest, indicating stability of these characteristics in this genotype.

According to phenotypic data, the projections of the variables loaded in the plane of the first two principal components explained approximately $64 \%$ of the observed variation (Figure 1). The YIE, NFD, DF, and EH correlated positively with

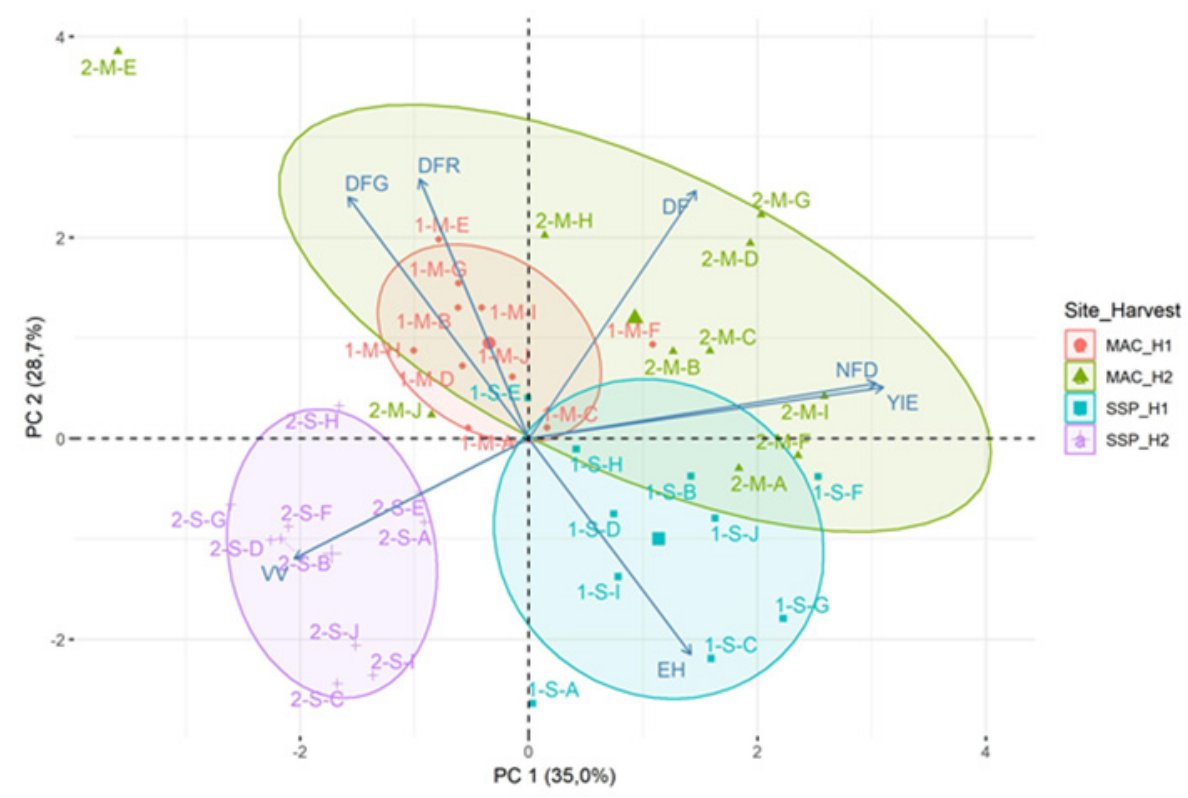

Figure 1. Projection of the variable loading on the plane of the principal components. The size of the vectors (arrows) represents the correlation between a variable and a PC. The PCA biplot shows the loading of each variable (arrows) and the scores of each progeny (points) for the first two principal components. The following identification was used: the number represents the harvest (1 or 2); the letter refers to the location (S: São Sebastião do Paraíso or M: Machado); and the last letter refers to the identification of progeny. Ellipses represent $69 \%$ of the scores for each group (formed by the site and harvest: MAC_H1: Machado harvest 1; MAC_H2: Machado harvest 2; SSP_H1: São Sebastião do Paraíso harvest 1 and SSP_H2: São Sebastião do Paraíso harvest 2), which are differentiated by colour. Variables: yield (YIE), natural fruit drop (NFD), defoliation (DF), vegetative vigor after harvesting (VV), efficiency of fruit harvest $(\mathrm{EH})$, and green and ripe fruit detachment strength (DFG, DFR). 
Table 1. Genotypic correlation among yield (YIE), natural fruit drop (NFD), defoliation (DF), vegetative vigor (VV), efficiency of fruit harvest (EH), ripe fruit detachment strength (DFR) and green fruit detachment strength (DFG) variables.

\begin{tabular}{lccccccc}
\hline Traits & YIE & NFD & DF & VV & EH & DFR & DFG \\
\hline YIE & 1 & 0.73 & -0.04 & -0.19 & -0.19 & -0.13 & -0.08 \\
NFD & & 1 & $0.70^{* *}$ & 0.01 & -0.13 & -0.25 & -0.12 \\
DF & & & 1 & $0.70^{* *}$ & -0.08 & -0.17 & -0.16 \\
VV & & & 1 & 0.01 & -0.10 & -0.16 \\
EH & & & & 1 & $-0.72^{* *}$ \\
DFR & & & & & 1 & 0.09 \\
DFG & & & & & & 1 \\
\hline
\end{tabular}

** Significant at $1 \%$ probability according to the Student's $t$-test.

PC1. However, the first two variables had larger squared loadings indicating that they contributed most to the variation observed. Moreover, these variables were strongly correlated with each other, because the angle formed by the projection of the vectors was close to zero. The DF and EH were less correlated. The VV, DFG, and DFR variables were negatively correlated with PC1, and the VV variable had the highest negative correlation and lowest $\cos ^{2}$ (approximately 0.5 ) compared with the others, which indicated that around $50 \%$ of the variation of this variable was not retained in the first two principal components. NFD and YIE with VV, EH with DFG and DFR, as well as VV with NDF and YIE and also VV with DF were negatively correlated due to the opposing directions of their vectors. This negative correlation between VV and YIE in coffee has been reported by other authors (Oliveira et al. 2011).

To verify if the genetic associations between variables followed the same pattern of phenotypic correlations we estimated the genotypic correlations. The YIE variable was not correlated to any other, indicating that the genetic variation was independent. We observed highly significant positive genotypic correlations between DF and NFD, DF and VV, and DFR and DFG, varying between 0.66 and 0.70 (Table 1). On the other hand, the EH and DFR, and also EH and DFG characteristics showed highly negative correlations. Plant defoliation led to a decrease in the fruiting of the coffee tree by lowering the reserves necessary for the formation of the fruits, which consequently decreased its production. Therefore, it is important to evaluate the amount of defoliation present in each of the operations (Tavares et al. 2019). Abscission of leaves, flowers, and fruits is a highly regulated phenomenon involving structural, biochemical, and molecular changes. It begins with the loosening of the cell wall within the zone as a result of the dissolution of the middle lamella and is followed by complete enzymatic degradation of the cell wall as described by Brandão et al. (2016).

It is important to note that the variables DFG and DFR were strongly correlated since the angle formed by the projection of its vectors was small, slightly larger than that formed by the variables YIE and NFD, which were also correlated (Figure 1, Table 1). These results indicated that the mean fruit detachment strength for each cultivar remains the same at both stages. The difference between fruit removal force for immature and ripe fruit is a significant indicator of the degree of selectivity actually achieved (Silva et al. 2013). The studied progenies did not show this selectivity.

It was also observed that the lower DFG and DFR, the higher the EH. The mechanized harvesting of coffee fruits is carried out by mechanical vibrations, a principle based on the transfer of vibrational energy to the fruit-peduncle system promoting the detachment of coffee fruits (Santos et al. 2010). The smaller this force at the peduncle the more efficient was the harvest.

In order to analyze if these variables could be used in the selection process, we estimated the genetic parameters (Table 2). The most heritable variable was DFR (0.89) and the variation in YIE was completely environmental $(0.01)$. The characteristics NFD, and DFG showed moderate heritability at the progeny mean level (54\%, $55 \%$, respectively), indicating that selection could be possible, but environment also had some influence.

The coefficient of determination due to the permanent environment effects was $0.06,0.12$ and 0.70 for EH, DF and DFG characteristics respectively. These values showed a permanent environment effect. So the variation present in DFG was due mostly to this effect. The coefficient of determination of the genotype $\times$ local interaction varied from 0.07 to 0.19 for YIE, NFD, DF, VV, and EH. The genotypic correlations between environments were high to moderate for DFR, 
Table 2. Estimates of genetic and phenotypic parameters related to efficiency of fruit harvest (EH), natural fruit drop (NFD), vegetative vigor after harvesting (VV), green and ripe fruit detachment strength (DFG, DFR), defoliation (DF), and yield (YIE) and estimates of the components of mean: predicted additive genetic value (û+â) and predicted additive genetic gain (SG\%) related to EH, NFD, $V V$, DFR, and DFG traits from in $\mathrm{F}_{3: 4}$ generation derived from 'Icatu' and selected for efficiency of fruit harvest (EH) in $\mathrm{F}_{3: 4}$ generation derived from 'Icatu'.

\begin{tabular}{lccccccc}
\hline Parameter $^{1}$ & EH & NFD & VV & DFR & DFG & DF & YIE \\
\hline$\sigma_{g}^{2}$ & $1.03^{*}$ & $2.38^{*}$ & $0.07^{*}$ & $0.22^{*}$ & $0.10^{*}$ & 0.00 & 0.28 \\
$c_{p e r}^{2}$ & 0.06 & 0.00 & 0.01 & 0.00 & 0.70 & 0.12 & 0.00 \\
$c_{\text {int }}^{2}$ & 0.07 & 0.07 & 0.11 & 0.00 & 0.00 & 0.13 \\
$\mathrm{~h}_{m g}^{2}$ & 0.40 & 0.59 & 0.34 & 0.89 & 0.56 & 0.03 & 0.01 \\
$r g_{e n v}$ & 0.45 & 0.17 & 0.33 & 0.99 & 0.75 & 0.03 & 0.00 \\
Mean & 94.74 & 8.47 & 6.80 & 3.66 & 6.58 & 0.44 & 39.01 \\
\hline Progenies & $\mathrm{u}+\mathrm{g}$ & $\mathrm{u}+\mathrm{g}$ & $\mathrm{u}+\mathrm{g}$ & $\mathrm{u}+\mathrm{g}$ & $\mathrm{u}+\mathrm{g}$ & \\
\hline $\mathrm{G}$ & 95.26 & 8.10 & 6.66 & 4.23 & 6.45 & \\
$\mathrm{H}$ & 95.20 & 6.81 & 6.62 & 4.16 & 6.84 & \\
$\mathrm{~J}$ & 95.13 & 7.62 & 7.00 & 3.63 & 6.45 & \\
$\mathrm{~F}$ & 95.05 & 10.41 & 6.53 & 3.83 & 6.38 & \\
\hline SG (\%) & 0.18 & -1.67 & -0.50 & 7.30 & & -0.42 \\
\hline
\end{tabular}

${ }^{1} \sigma_{g}^{2}$ : genotypic variance, $c_{p e r}^{2}$ : coefficient of determination of the effects of permanent environment, $c_{\text {int }}^{2}:$ coefficient of determination of the effects of genotype $\times$ local interaction, $\mathrm{h}_{m g}^{2}$ : heritability of progeny mean, assuming complete survival, $r g_{e n v}$ : genotype correlation between performance in environments. Overall mean of the experiment. *Significance, determined by likelihood ratio test, at $5 \%$ probability.

DFG and EH. For the other variables this estimate was low and showed that the performances of progenies for these characteristics were inconsistent.

The choice of NDF, VV, EH, DFR and DFG for selection of progenies was based on genotypic variance. We consider $\mathrm{EH}$ the main criterion for the selection of coffee trees, and the progenies $\mathrm{G}$ (H 105-01-39 cv 4), H (H 107-47-02 cv 1),

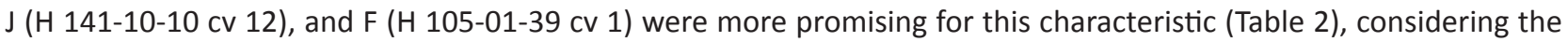
selection intensity of $40 \%$ for the advancement of generations. It is observed that the progenies derived from IAC 5002 were as three of the four best-classified progenies. 'IAC 5002' was obtained from Mundo Novo and Catuai Amarelo crossing. The satisfactory performance of their parents in relation to fruit removal force was reported in the literature (Crisosto and Nagao 1991). The selection of progenies F, G, H and J, favored genetic gains regarding the genotypic mean of the assay, in the order of: $1.67 \%$ decrease in NDF, $0.50 \%$ decrease in VV, $0.18 \%$ increase in $\mathrm{EH}, 7.30 \%$ increase in DFR and $0.42 \%$ in decrease DFG. The selected progenies did not present yield gains, however, they were in $\mathrm{F}_{4}$ generation and represented promising alternatives for new cultivar development. Our results reinforced the superiority of these progenies which were previously evaluated in field conditions by Pereira et al. (2013). A resistant cultivar with desirable agronomic characteristics, and also adapted to mechanical harvest could be easily obtained in subsequent selections.

Little was known about the detailed interactions between genotypic and phenotypic correlations among semimechanized harvesting characteristics. The yield showed almost no genetic tendency, indicating that the selection used in the population did not improve this characteristic. The selection have been used to enable gain for $\mathrm{EH}$, leading to improvements in most, but not all, traits. In this way, the gain in efficiency of fruit harvest, the initial objective of the work, must be emphasized. In this study, we proposed ways to improve semi-mechanized harvesting through plant selection. We identified progenies more adapted to the semi-mechanized harvest, and, thus, supported our hypothesis about the utility of harvesting characteristics as selection criteria. Findings from this research will be useful for efficient planning of future research involving breeding programs to improve semi-mechanized harvesting of coffee.

\section{ACKNOWLEDGMENTS}

To the National Science and Technology Institute (INCT-Café/CNPq), to the Coffee Research Consortium, and the Research Support Foundation of the State of Minas Gerais (Fapemig) for financial support for the project. To the fellowship of research productivity (PQ) granted by the National Council for Scientific and Technological Development (CNPq) and Fapemig. The authors are grateful to reviewer for his contribution in this paper. 


\section{REFERENCES}

Brandão IR, Silva DM, Souza KRD, Vilas Boas LV, Santos MO, Silva FM and Alves JD (2016) Physiological and ultrastructural analysis reveal the absence of a defined abscission zone in coffee fruits. Bragantia 75: 386-395.

Carvalho A, Mônaco LC and Fazuoli LC (1979) Melhoramento do café. $\mathrm{XL}$ - Estudos de progênies e híbridos de café Catuaí. Bragantia 38: 202-216.

Crisosto CH and Nagao MA (1991) Evaluation of fruit removal force of coffee cultivars Hortscience 26: 210.

Cruz CD (2013) GENES: a software package for analysis in experimental statistics and quantitative genetics. Acta Scientiarum. Agronomy 35: 271-276.

Ferreira Junior LG, Silva FM, Ferreira DD and Sales RS (2016) Recomendação para colheita mecânica do café baseado no comportamento de vibração das hastes derriçadoras. Ciência Rural 46: 273-278.

Huang M and Zou Y (2018) Integrating mechanization with agronomy and breeding to ensure food security in China. Field Crops Research 224: $22-27$

Oliveira ACB, Pereira AA, Silva FL, Rezende JC, Botelho CE and Carvalho GR (2011) Prediction of genetic gains from selection in Arabica coffee progenies. Crop Breeding and Applied Biotechnology 11: 106-113.
Pereira TB, Felicori JPC, Botelho CE, Resende MDV, Rezende JC and Mendes ANG (2013) Eficiência da seleção de progênies de café $F_{4}$ pela metodologia de modelos mistos (REML/BLUP). Bragantia 72: 230-236.

R Core Team (2019) R: a language and environment for statistical computing. R Foundation for Statistical Computing. Available at <http://www.R-project.org/ add>. Accessed on February 18, 2019.

Resende MDV (2016) Software Selegen-REML/BLUP: a useful tool for plant breeding. Crop Breeding and Applied Biotechnology 16: 330-339.

Santos FL, Queiroz DM, Pinto FAC and Resende RC (2010) Efeito da frequência e amplitude de vibração sobre a derriça de frutos de café. Revista Brasileira de Engenharia Agrícola e Ambiental 14: 426-431.

Silva FC, Silva FM, Silva AC, Barros MM and Palma MAS (2013) Desempenho operacional da colheita mecanizada e seletiva do café em função da força de desprendimento dos frutos. Coffee Science 8: 53-60.

Silva FC, Silva FM, Alves MC, Ferraz GAS and Sales RS (2015) Eficiência da colheita mecânica e seletiva do café em diferentes vibrações, ao longo do período de colheita. Coffee Science 10: 56-64.

Tavares TO, Oliveira BR, Silva VA, Silva RP, Santos AF and Okida ES (2019) The times, movements and operational efficiency of mechanized coffee harvesting in sloped areas. PLoS ONE 14: e0217286. 